\title{
EVOLUCIÓ SEMÀNTICA D'ARRIBAR EN CATALÀ (SEGLES XIII-XVI): UN EXEMPLE DE CANVI DE PROTOTIPUS
}

\author{
SANDRA MONTSERRAT \\ Universitat d'Alacant \\ Sandra.Montserrat@ua.es
}

\begin{abstract}
Resumen
The semantic structure that the verb «arribar» currently presents in Catalan is the fruit of the complex history of semantic changes that have provoked the category's expansion from the basic core. In this work we pretend to follow the diachronic ways of these semantic changes from the theory of prototypes effects (Geeraerts. 1997:22). As a result, we offer the semantic net of the verb "arribar», from the exhanstive analysis of the contextual uses through 13th, 14th, 15th and 16th centuries.
\end{abstract}

\section{OBIECTIUS I HIPÒTESI ${ }^{1}$}

\subsection{Els efectes de prototipicitat}

L'estructura semasiològica que presenta arribar en català en l'actualitat és fruit d'una història complexa de canvis semàntics que han provocat l'eixamplament de la categoria a partir d'un nucli bàsic. En aquest treball pretenem reseguir les dreceres d'aquests canvis semàntics en diacronia; com a resultat, oferirem la xarxa semàntica del verb arribar, a partir de l'anàlisi exhaustiva dels contextos d'ús al llarg dels segles XIII, XIV, XV i XVI.

Seguirem la proposta d'anàlisi de Geeraerts (1997:22) sobre els efectes de prototipicitat, perquè considerem que il-lustra les possibilitats de la teoria del prototipus, explicita la importància dels mecanismes bàsics del canvi semàntic — la metàfora i la metonímia- i, finalment, descobreix el valor just dels factors contextuals (experiencials i culturals, etc...) en qualsevol procés d'extensió semasiològica. Comptat i debatut, volem oferir una mostra més de la contribució als estudis sobre el significat de la semàtica diacrònica de base cognitiva ${ }^{2}$.

\footnotetext{
1 Aquest article és una ampliació de la comunicació presentada en el en el $V$ Congreso de Lingüistica General, celebrat a Lleó el 5, 6, 7 i 8 de març del 2002, titulada: «Evolución semántica y usos metafóricos y metonj́micos del verbo venir, arribar y aplegar en textos catalanes del XIV al XIX).

2 Altres treballs anteriors en aquest mateix sentit són els de Soares da Silva (1997) per a deixar en portugués i Martines (2000), en relació amb cl verb estimar del català.
} 
En primer lloc, seguint Geeraerts (1997:22) considerem que l'eixamplament de la categoria representada per arribar pot explicar-se a partir de dos efectes de prototipicitat bàsics, resultat d'una de les característiques principals de les categorics: la no-igualtat en la extensió i intensió de la categoria. Observarem com arribar varia de prototipus (efecte 1'la modulació dels centres prototípics') i, en scgon lloc, mostrarem com aquesta modulació es produeix a partir de l'alteració en l'agrupació del sentits per semblances de familia (efecte 2).

A l'últim, explicitarem, a més a més, com les modulacions en l'estructura semasiològica de la categoria representada per arribar s'han d'entendre com a transformacions d'imatges esquemàtiques, a partir d'un esquema bàsic de moviment; és a dir, com a projeccions a diverses realitats de models esquemàtics creats per l'experiència amb el món. En aquest sentit, afegim a la hipòtesi de Geeraerts, la hipòtesi de Lakoff (1987) i Johnson (1987) sobre les transformacions d'imatges esquemàtiques.

\subsection{Les dades i el tractament estadístic}

Com és ben sabut, per a la semàntica cognitiva destriar el camí d'extensió semasiològica d'un mot és una tasca fonamentada en la interpretació dels contextos d'ús. Sovint, el mètode interprelatiu ha estat criticat per dues raons: en primer lloc, la subjectivitat que a voltes implica escatir el sentit d'un mot en un context determinat; en segon lloc, la multiplicitat d'hipòtesis que es poden oferir a l'hora d'explicar l'origen dels diversos sentits traslladats. Tot plegat ha provocat que els viaranys que desemboquen en la polisèmia d'un mot hagen estat considerats atzarosos i poc sistematitzables.

Com provarem de fer veure, precisament aci es troba l'encert de la gramàtica cognitiva. Ens basteix de conceptes teòrics que remeten a regularitats bàsiques en qualsevol canvi semàntic: en aquest cas, els viaranys de què parlàvem es descriuen per la prototipicitat.

En aquest treball, a més, volem insitir en el fet que si unim la teoria a un bona arreplega de dades de la llengua objecte d'estudi, la predicció dels camins que recorre el canvi lèxic es fa encara més clara. Per aquest motiu ens hem bastit d'un corpus extens de 109 textos del català des del segle XIII al XVI, dels quals hem tractat informàticament $92 .^{3}$

Cada vegada és més habitual trobar estudis que recorren a corpora tractats informàticament (cf. Ramos Alfajarín 2000: 39) i que, per tant, permeten obtenir no solament dades qualitatives, sinó també dades quantificables sobre un fenomen lingüístic concret. Aquest fet augmenta el rigor metodològic de les anàlisis lingüístiques. Tanmateix, l'avantatge és encara més gran quan ens enfrontem amb textos en llengua antiga, perquè, a ulls de l'investigador, aquesta es presenta, ben bé, com si fos una altra llengua i la intuîció com a parlant deixa de ser un recurs complementari, almenys parcialment.

3 No reproduïm el corpus per problemes d'espai. Es pot consultar en http://www.ua.es'personal/sandra/tesiscorpus.htm 


\section{ESTRUC'IURA SEMASIOLO'GICA D'ARRIBAR}

\subsection{Arribar: terme mariner}

Bastardas (1996: 100) i el DECat (s.v. arribar) coincideixen a afirmar que arribar es documenta en català a finals del segle XIII ${ }^{4}$, i dc primer, va ser un terme nàutic que significava 'atracar (una nau), arribar a port o platja' (a partir d'ara sentit A).

A partir del corpus analitzat, podem comprovar com els primers valors d'arribar es documenten en textos de la segona meitat del segle XII i de principis del segle XIII, i responen al sentit A. Així, pcr exemple, l'exemple 1. N'oferim també exemples en altres segles:

(1) Nós no prenam ne alcú no prena ne deman alcuna cosa per dret o per occasió de naufraig de les naus ne de leyns ne de les coses ne dels esmerçamens ne dels hòmens de qualque loch que seran, estrayns o privats, ne de les coses d'aquells qui arribaran o trencharan per perill de mar o per tempestat dins lo terme del regne e de la ciutat de València (Furs $\sim X I I-1 / X I V$, Rúb. 130, lin. 4)

(2) [... ell estant en la illa de Anglaterra, en les parts de Comualla, en lo port de Falamua, ab una nau de Gal.licia appellaldaJ Sancta Maria, de la vila de Pontovedre, carregada e espalxada aci, en València, de diverses mercaderies sues e d'altres mercaders companyons scus d'aquesia ciutat -- en lo qual port era arribat per força de mal temps-, una barxa armada de gents d'armes de Lesbona vench de sobre la dita nau e la pres [...] (Epist_valencia2 2/XIV, p. 145, caria 48, lin. 12)

(3) E soltes les cordes e levades les ànchores, e alçades les velas en alt, les nous, en num dels déus Jípiter e Venus, en la alta mar se empenyen, e axi navegant arribaren en unas ylles de Romania appellades Ciclades (Troianes 2/XIV, p. 38rb)

(4) Dilluns, a II de ffabrer MCCCCXXXVIIII, arribaren en la plaja de Barchinona aquelles III naus armades de mossèn Riembau de Corbera [...] (Safont_dietari 2/XV, p. 81, lin. II)

(5) La nat és arribada la nit de cincogesma en lo present port; passades les festes, plaent a Déu la descarregaran (Epistolari_Cahner2_oriental 1/XVI, p. 141, lin. 24)

(6) En lo any cinch-cens trenta-y-cinch, en lo mes de mars, arribaren naus en Sivilla que portaren molt or e argent per a l'emperador (Germanies -1/XVI, p. 405, lin. 20)

(7) [...] ab dos parells de rems trobaren a la vora del riu, tiraren la volta de la mar, y exit ab aquella, foren guiats ab bon salvament en Alexandria de ahont eren los dos naturals. Los quals aprés de arribats tenien memòria de la tan senyalada mercè per medi de la sacratíssima Senyora rebuda (Despuig colloquis $2 / X V I, p .82$, lin. 3i)

4 Bastardas (1995: 123) apunta que el verb arribar és indubtablement un mot bàsic del català, però, com s'ha esdevingut a callar, cercar, trobar i treballar, encara no se n'ha trobal documentació primerenca. Així també cs pot comprovar en el corpur que hem analitzat. No apareix en cap dels tcxtos dels segles XI-1/XII, ni tampoc en textos de la segona meitat del XII ni de la primera meitat del XIII. LI DECat proposa que arribar parteix d'un llati vulgar *arripare, com a terme mariner; per tant, el sentit actual que pren el verb arribar en llengües com el català o el francés es produeix en romànic. 
(8) Dijous, a XXIIII. de setembre del any MDLXXXXVIII., estant los senyors concellers congregats ab la vuytena de guerra dins lo baluart de mix jorn, per causa que setze galeres de Gènova eren arribades en la nit y avien surgit dins del moll sens saludar la Ciutat, com tenien obligatió (Solemn_barcelona4 2/XVI, p. 99, lin. 7)

A la vista dels exemples anteriors, podem apuntar que el verb arribar segueix l'esquema bàsic del —CAMí- (cf. Johnson 1987: 126; Lakoff 1987: 283), amb un TRAJECTOR, normalment una cosa en moviment, el vaixell (cf. 2) o bé la tripulació del vaixell (cf. 7), que aconsegueixen una FITA, el lloc on la nau finalitzarà el viatge, com ara la platja (cf. 4) i el port (5) o bé, la ciutat o poble on es troba el port en qüestió (cf. 3 i 6). Tanmateix, la FITA, pot no aparéixer si es recupera pel context (cf. 8).

Com suggereix la figura 1, el predicat més freqüent (el $95 \%$ dels casos) que vehicula el sentit A d'arribar consta d'un TRAJECTOR, [agent] que inicia el moviment i una FITA, lloc on finalitza el moviment - en forma de CC de lloc. Coincideix, per tant, amb l'estructura central (core-structure. cf. Talmy 1996a: 238) establida per a una situació de moviment amb desplaçament i que anomenarem DIRECCIÓ-FITA En la figura 2 n'oferim les correspondències sintàctiques:

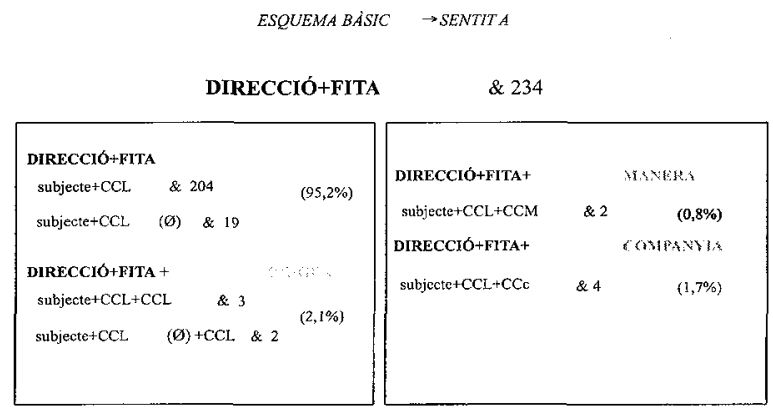

Fig. 1. Imatge esquemàtica bàsica d'arribar, sentit $\mathrm{A}$

\begin{tabular}{|c|c|c|c|}
\hline TRSECIUR & 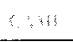 & arrecen & $\mathrm{ma}$ \\
\hline [agent] & \multicolumn{2}{|c|}{ Moviment } & \multirow{3}{*}{$\begin{array}{l}\text { [locatiu] } \\
\text { SP }\end{array}$} \\
\hline Substantiu & Verb & prep & \\
\hline Subjecte & \multicolumn{2}{|c|}{ Predicat (nucli+CCL) } & \\
\hline
\end{tabular}

Fig. 2. Correspondències semàntiques, morfològiques i sintàctiques en venir

$5 \quad$ Les dades que es presenten després del símbol \& es refereixen al nombre de vegades que apareix l'esquema en el corpus. El conjunt buit $(\emptyset)$ indica que el CCL no apareix explícit. 
A aquest esquema pot afegir-se circumstancialment l'ORIGEN $(2,1 \%$ dels casos, cf. exemple 9), la MANERA $\left(0,8 \%\right.$ dels casos, cf. exemple 10) i la COMPANYI ${ }^{6}$ (cf. $1,7 \%$ dels casos, cf. exemple 11).

(9) Dimarts, a XXV de noembre del any MCCCCXXXVIII, hora tarda, arribaren dues galees de mercaderia de les parts de Levant, les quals patronejaven (Solemn_barcelona1 l/XV, p. 95, lin. 7)

(10) Dissabte, a XXI. de janer, any de la Nativitat de Nostro Senyor MCCCLXIIII, lo illusire senyor rey en Pere, rey d'Aragó [...] venint de les parts de Portogal com a rey e senyor novament en la present ciutat elet, arribá en la present plage de la mar de Barchinona ab dues galeas d'en Rafel Julià (Solemn_barcelona2 2/XV, p. 274, lin. 12)

(11) [...] lo rey Teotran $a b$ molts cavellers e ab moltes companyes de peu vengren a la riba de la mar, on Achilles e Tèlafus eren arribats en companyia dels seus (Troianes $-2 / X T V, 57 \mathrm{va})$

En conseqüència, la imatge csquemàtica bàsica del verb arribar, en aquest primer sentit, ens remet a un esdeveniment puntual de caràcter culminatiu, que implica un canvi de localització; en terminologia de Vendler (1976), un assoliment. No és estrany aquest esquema tèlic, atés que 'aturar-se en una riba' és el darrer moment de moviment que realitza un vaixcll. Com s'esdevé als predicats puntuals, el verb arribar va sovint acompanyat de sintagmes, en funció de CC de temps, que indiquen el moment de l'arribada. En són bons exemples alguns dels contextos anteriors $(4,5 \ldots)$.

Igualment, l'aspecte verbal, vehiculat a través dels diverses formes verbals, accentua el caràcter culminatiu de l'acció expressada per arribar. Les dades que presentem en la figura 3 , mostren que la majoria de les voltes que trobem el verb arribar en el sentit A cstà conjugat en formes verbals perfectives? o en l'aspecte perfet; per tant, presenten l'acció d'arribar vista com un tot global delimitat, en el primer cas, o bé focalitzen el moment posterior de l'acció ja finalitzada, en cl segon cas. Per contra, és molt menys freqüent $(5,1 \%)$ trobar arribar en aspecte imperfectiu.

\footnotetext{
6 En aquest punt utilitzem MANERA en senít restringit, és a dir, solament per a indicar com cs realitza el moviment. Tot $\mathrm{i}$ que, en la teoria les imatges esquemàtiques no se sol inclourc l'element companYis entre els elements perifèrics el marquem ací per matisar un poc més cl tipus d'element que acompanyen l'esquema central.

7 Per a la terminologia verbal seguim Saldanya (2002: 2587)
} 


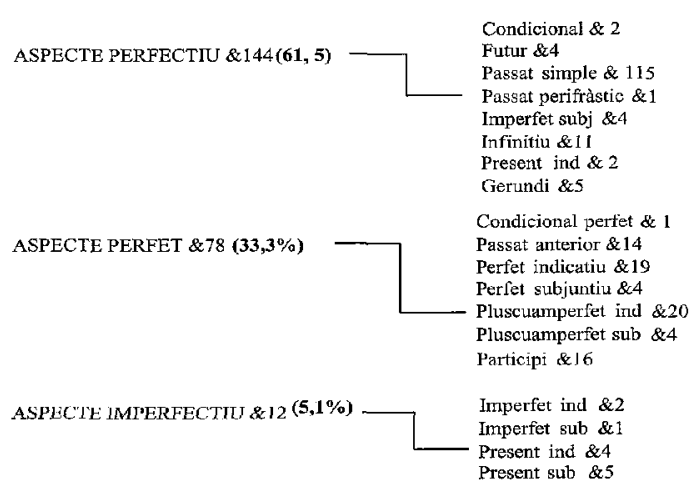

Fig. 3. L'aspecte en els temps verbals d'arribar A.

A voltes, sobretot en la forma de l'imperfet d'indicatiu, l'aspcete imperfectiu transforma l'assoliment en una realització, una siluació culminativa, però que consta d'un procés que té certa durada en el temps (Vendler 1976). En aquests tipus de contextos, el verb sembla que tinga un sentit pròxim a 'acostar-se a la riba':

(12) Arribava a la cruel ciutat de Plutó lo fill de Caliope quant Thesifone, ab les germanes, de no acostumades lagremes llurs spantosses cares regaven (Corella_proses 2 ) $X V$, p. 256, lin. 462)

\subsection{Primera modulació: un canvi de prototipus}

Tant pel que fa al textos literaris com no literaris, el sentit $A$ és gairebć cxclusiu, almenys fins a la segona meitat dcl XIV. Diem gairebé exclusiu, perquè hem trobat dos exemples de principis del segle XIV en els quals sembla que arribar té ja el valor actual de 'venir fins a un punt que es pren com a terme del moviment' (a partir d'ara, sentit B). L'exemple 13 és l'única aparició d'arribar en els Viatges de Marco Polo. De la mateixa manera, tan sols hem trobat un exemple d'arribar, cl número 14, en tot el corpus consultat de Llull:

(13) E aprés troba hom una bella ciutat qui ss'apela Guingui, qui és nobla e richa; e fan-s'i gran quantitatz de draps d'or de seda, ops de la cort del seyor; e ày moltz hostals per les viandes que y arriben aqui de diverses lochs a hobs de la lur cort del senyor [...] (Marco Polo XIII-I/XIV, p. 94, lín. 24).

(14) Los missatgers arribaren en la cort del leó (Liull Felix, pt. VII, c.5)

E1 DECat (s.v. arribar) apunta que, tot i aquestes aparicions esporàdiques, el verb arribar no es convertirà en el verb principal per a l'expressió general de qualsevol arribada en 
tot el català fins més tard. I això també sembla valer per a les altres llengües romàniques que comparteixen aquest verb amb la nostra llengua. Concretament, l'occità (cf. Levy, s.v. arribar), el francés (García-Pelayo \& Gross 1992: s.v. arriver), l'italià (cf. DLI s.v. arrivare) i el castellà (en algunes contrades, cf. DRAE, s.v. arribar).

Les dades obtingudes a partir del corpus despullat en aquest treball confirmen aquesta hipòtesi del DECat (s.v. arribar) i mostren que el verb arribar amb el sentit B naix a la darreria del segle XIII, primeries del segle XIV; tanmateix, no es farà habitual en el sentit B fins ben entrat el segle XV. Les figures 4 i 5 suggereixen aquesta tendència'; així, en obres no literàries, com ara els Furs o en el Llibre de Solemnitats de Barcelona i en obres literàries, com els Feyts, la Crònica de Muntaner, la Crònica de Desclot o les Troianes, no hi apareix mai el sentit B. En canvi, ja el trobem en obres de la primera meitat del segle $\mathrm{XV}$, com el Curial i, sobretot, és habitual en els segles posteriors. Fins i tot, el sentit A ja no apareix mai en obres del segle XV, com el Somni de Francesc Alegre, Despropiament d'Amor o l'Spill de Jacme Roig; i és estrany en obres del segle XVI, com 1'Epistolari d'Estefania de Requesens (una volta el sentit A, davant 138 del sentit B), les Germanies (cinc ocurrències del sentit $\mathrm{A}$, davant 64 del sentit $\mathrm{B}$ ) o els Colloquis de Despuig (només un cas de sentit marítim) $)^{10}$ :

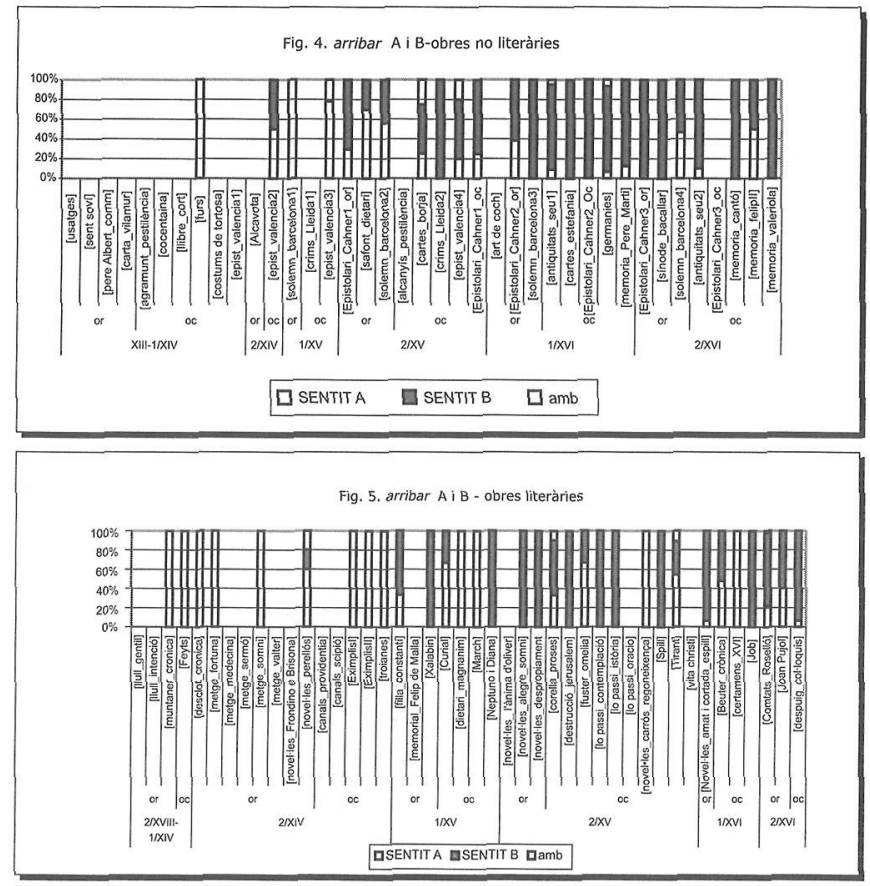

9 Les gràfiques d'aquest capítol es presenten en tant per cent (\%), quan aquesta referència ens permet veure millor la relació de freqüències entre els diversos sentits.

10 En les gràfiques presentades utilitzem l'abreviatura amb amb el sentit ambigu. 
A continuació oferim uns quants exemples que il-lustraran les dades de les figures anteriors:

(15) Oo, què cena! E, de aquells qui volen haver bon dinar, pren-los enaixi com a aquell qui arribe a hum hostal e demane: "Ara dat-me cinvada e palla; ara dat-me pa e vi; ara açò, e açò» (Vicent_sermons $\sim 2 / X I V$, vol. II, p. 36, lin. 27)

(16) [...] e axi lo dit germà de Johan de Balda dix a ell testis: «dezit a-vuestro hamo que se guarde, que jo serà alà algun día e li tornarem lo guardó e nos traharemos, $e$ dezigelo!», e ell testis dix: "ja-u-faré», $e$ axi arihat en Leyda o dix a son amo (crims_Lleida2 $2 / X V$, p. 71 , lin. 123)

(I7) E a poch instant, a la gran rumor, e sentint ço que dit és, arribaren alli mateix tres de nosaltres, fahent tocar grans colps a la dita porta per entrar en la dita casa e parlar ab lo dit comte, pregar e requerir-lo no procehis pus avant contra lo dit home en dia de Pascua e feriat (Epist_valencia4 2/XV, p. 347, carta 138, lín. 18)

(18) D'aqui parti la professó per la Verge Maria de Sperança, y arribà a Sent Pere, y vesitaren lo Corpus de Sent Pere, cantant lo vers dels Apostols. D'aqui parii la professó a les fonis y vesitaren les fonts (Antiquitats_seu1 1/XVI, p. 40, § 5 cap. 2)

(19) A 19 del mes de janer 1586, diumenge, a les 12 hores de migjorn, entrà en València el serenisim senyor rey don Phelip 2, juntament ab lo princep don Felip 3 y la serenisima ynfanta donya Ysabel Eugènia, sos fills, havent partit aquell dia del convent de Sant Miguel de los Reyes, a hon a 16 de dit mes y any havien aplegat. Arribaren al portal de Serrans, lo qual a la part de fora estava molt ben aderesat (Mernòria_FelipII 2/XVI, p. 125, lin. 6)

En el moment que comencen a donar-se els sentits A i B en una mateixa obra, com s'esdevé ja en obres de la segona meitat del XIV (cf. Epistolari Valencià2 o el Viatge de Perellós), sovint trobem contextos ambigus (apareixen comptabilitzats en la figura 4 i 5 . Sobretot, si no apareix explícit el CAMÍ que se segueix i hom té la possibilitat d'arribar al lloc de destinació tant per mar com per terra. En són bona mostra els exemples següents:

(20) [Barcelona, 16 setembre 1493] Sanzctissime ac beatissime pater: Aprés de besar humilment los peus de vostra santedat. Ahir, que comptàvem quinze del present, arribà aci l'embaixador del rei de França, qui es diu lo Paneter, germà del bisbe de Frijuis, qui és en aqueixa cort de vostra santedat. Cartes_borja 2/XV, p. 42, lin. 4)

(21) Embaxadors dels estaments anaren a sa Magestad y'ls respongué que ja y havia virrey. Los embaxadors del bras militar arribaren a la Corumya ahon sa Magestad era arribat y esperava la armada per a enbarcar-se per a Flandes y Alemanya per a coronar-se de emperador (Germanies $1 / X V I, p, 106$, lín. 15)

En la figura 6 presentem els tipus de predicats que hem constatat $\mathrm{cn}$ cl nostrc corpus en relació amb el sentil $\mathrm{B}$ i en la figura 7 les correspondències sintàctiques de la imatge esquemàtica principal. Com adés hem observat per al sentit $\mathrm{A}$, el predicat més freqüent consta d'un TRAJECTOR i una FITA, explícita o recuperable pel context (92,9\% dels casos): 
ESQUEMA BÀSIC $\rightarrow$ SENTIT B

DIRECCIÓ+FITA \& 567

\begin{tabular}{|c|c|}
\hline $\begin{array}{l}\text { DIRECCIÓ + FITA } \\
\text { subjecte+CCL \& } 381 \\
\text { subjecte+CCL (Ø) \& } 145\end{array}$ & $\begin{array}{l}\text { DIRECCIÓ + FITA + Cif SA } \\
\text { subjecte+CCL+CCF \& } 4 \\
\text { subjecte+CCL }(\varnothing+\text { CCF \& } 1 \quad(0,88 \%)\end{array}$ \\
\hline $\begin{array}{l}\text { DIRECCIÓ + FITA + } \\
\text { subjecte+CCL+CCL\& } 4 \\
\text { subjecte+CCL }(\varnothing)+C C L \& 12 \\
\text { DIRECCIÓ + FITA+ CABH } \\
\text { subjecte+CCL+CCL\& 2 }\end{array}$ & $\begin{array}{l}\text { DIRECCIÓ + FITA + MAYZRA } \\
\text { subjecte+CCL }(\varnothing)+C C M \& 2 \\
\text { DIRECCIÓ + FITA + COMpANXIA } \\
\text { subjecte+CCL+CCc \& } 3 \\
\text { subjecte+CCL }(\varnothing)+C C c \& 13\end{array}$ \\
\hline
\end{tabular}

Fig. 6. Imatge esquemàtica bàsica d'arribar, sentit $\mathrm{A}$

\begin{tabular}{|c|c|c|c|}
\hline TRABLCTOR & сымi & DIRECOO & rTa \\
\hline [agent] & movi & & [locatiul] \\
\hline Substantiu & verb & prep & SP \\
\hline Subjecte & Predi & & \\
\hline
\end{tabular}

Fig. 7. Correspondències semàntiques, morfològiques i sintàctiques en venir

Són ben pocs, en canvi, els casos en què s'afigen altres elements, com ara la MANERA, l'ORIGEN, la COMPANYIA i la CAUSA:

(22) E, aprés, tocades ja les quatre hores, arribà lo dit senyor rey, a cavall, acompanyat del marqués de Dénia, qui portave lo stoch devant, (Solemn_barcelona4 2/XVI, $p$. 138, lin. 21)

(23) En hun troter, / ab prou dinés, / ell me tramés / ben arreat, / cami ferrat, / per Tarraguona / a Barcelona. / Quant arribi, / de sent Marti / castell fort pres, / en Penedés (Spill 2/XV, v. 333)

(24) Y tantost arribà don Pero Maça ab 80 homes de a cavall, gent molt lúcida (Germanies 1/XVI, p. 183, lin. 4)

(25) [...] ara per ofendre mas per jutjar arriba, mostrant-se a tal acte conforme (Novel-les_alegre_somni $2 / X V, p .126$, lín. 19)

També tenim exemples amb l'element CAMí explicitat. L'aparició d'aquest element és una mostra més que el verb arribar serveix per a qualsevol tipus de desplaçament i que, per tant, a vegades cal especificar com hom arriba: 
(26) E irum dit mossèn Hierònim e jo; lo qual estava ja aparellat per anar ans de la venguda d'aquest correu, sabent, per alguns qui eres arribat per terra, que es podia passar, e que no es donava empatx a negu (Cartes_borja 2/XV, p. 160, lin. 17)

Amb les dades que hem presentat es pot deduir que tots els elements de la imaige esquemàtica del sentit $\mathrm{A}$ es conserven també per al sentit $\mathrm{B}$ d'arribar. Per tant, la imatge esquemàtica del nou sentit ens remet també a una acció de poca durada, de la qual focalitzem el final, en terminologia de Talmy (1996a: 272), parcel·lem la finestra final. Tal com s'ha dit per a $\Lambda$, el verb arribar, per tant, vehicula prototípicament un predicat tèlic de poca durada: un assoliment.

Novament (cf. figura 8), les formes verbals més habituals en què es conjuga arribar amb el sentit $B$, vehiculen l'aspecte perfectiu o perfet:

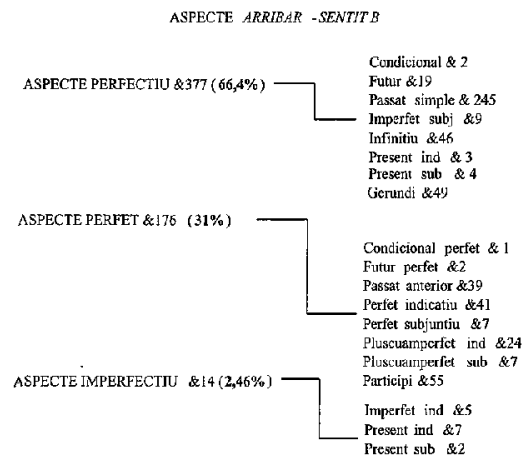

Fig. 8. L'aspecte en les formes verbals d'arribar, sentit B

En tan sols un 2,46\% dels casos l'acció es imperfectiva. En aquest cas, presenta una escena habitual:

(27) Cada dia ariben dames a palàsio y casen-se'n poques. Esta senmana se'n casa una néta del marquès de Cayete ab un oncle seu. jermà de sa mare, que par a totom cosa estroya no avent-y nesesitat de conservar béns com no la y à (Cartes_estefania 1/ XVI, p. 191, carta 62, lin. 27)

Tant el DECat (s.v. arribar) com Bastardas (1996: 97 i 100) estan d'acord a considerar que el sentit B parteix del sentit A. Concretament, el tecnicisme arribar es banalitza i passa a descriure qualsevol tipus de moviment; així també s'ha esdevingut amb altres verbs, com ara acostar ${ }^{11}$.

El naixement del sentit $B$ és el resultat de la projecció de 1'esquema inicial del sentit $A$, que hem descrit adés, cap a una altra realitat. En altres paraules, el parlant enriqueix

11 Actualment, encara es produeix aquest trasllat de termes mariners a àmbits de la llengua comuna. Als pobles de costa de la Marina Baixa s'utilitza el terme atracar-se per a indicar l'acció d'arribar o acostar-se: M'atracaré a ta casa a les huit (cf. Martines 1998: 177). 
— transforma - la imatge esquemàtica principal del verb arribar a partir de l'observació de la similitud entre dues accions 'atracar o acostar-se a la riba' $i$ 'arribar a un lloc'. Fet i fet, tan l'una com l'altra descriuen el moviment d'un TRAJECTOR cap a una FITA, per tant, l'extensió metafòrica, +ARRIBAR A LA COSTA ÉS ARRIBAR A Un LlOC+ és un pas realitzable amb facilitat.

Tammateix, solament es pot explicar la creació d'aquesta metàfora, és a dir, que el conceptualitzador considere igual 'atracar' que 'arribar', tenint en compte la realitat marinera del poble català. Com ja ha explicat Martines (2000: 1229) per a l'evolució semàntica d'estimar sols l'experiència dels parlants amb el món pot explicar les dreceres que recorre una categoria en el procés d'eixaplament. També el canvi en arribar s'ha d'explicar a partir de l'experiència amb el món. L'acció d'acostar-se les barques a la riba pren relleu onomasiològic solament en els pobles mariners. És a dir, aquesta acció pren importància perquè en els pobles mariners la forma més segura de viatjar, i la més freqüent, era el vaixell. Per tant, viatjar és sinònim de navegar.

Possiblement, aquest pas metafòric es va veure afavorit també, per contextos com els que hem apuntat adés, en els quals no apareix el lloc d'arribada explícit. A partir d'aquests contextos, el receptor pot arribar a inferir que el tipus de lloc on s'arriba no és solament el port, la costa o la platja. I precisament aquests contextos són una prova més dels límits difusos i, en conseqüència, flexibles, de les categories (cf. Geeraerts 1997:22).

El naixement del sentit B, doncs, eixampla la categoria representada per arribar. Les dades estadístiques confirmen quantitativament aquest fet. Les figures 9 i 10 presenten la freqüència total d'aparició d'arribar A i arribar B al llarg dels segles en tot tipus d'obres. $\mathrm{Hi}$ podem constatar que el naixement del sentit $\mathrm{B}$ provoca l'augment de la freqüència d'aparició del verb arribar a partir del segle XV, en tots els dialectes i també en tot tipus d'obres:

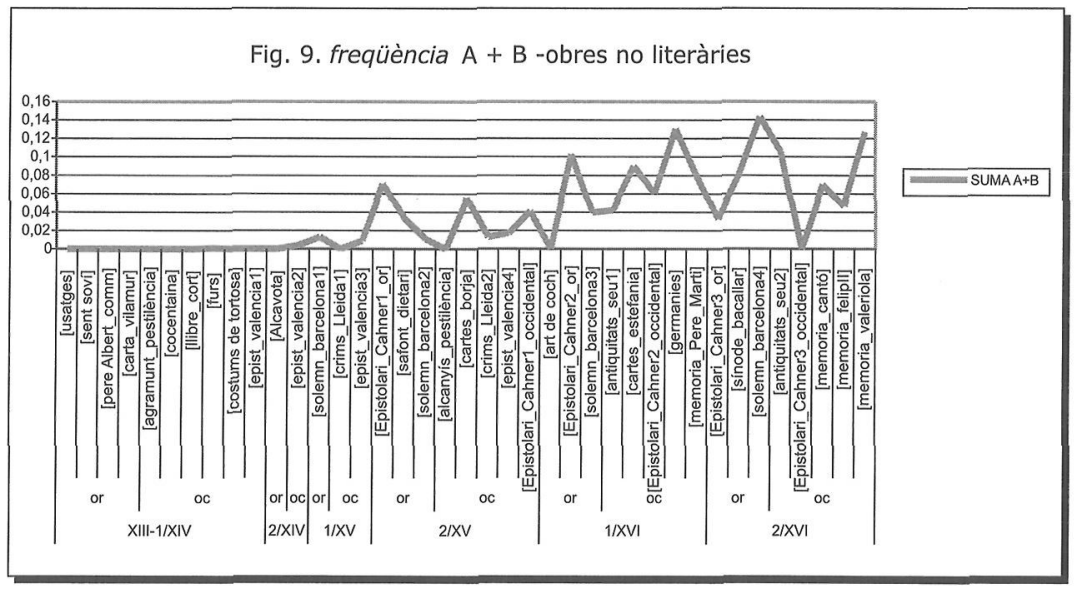




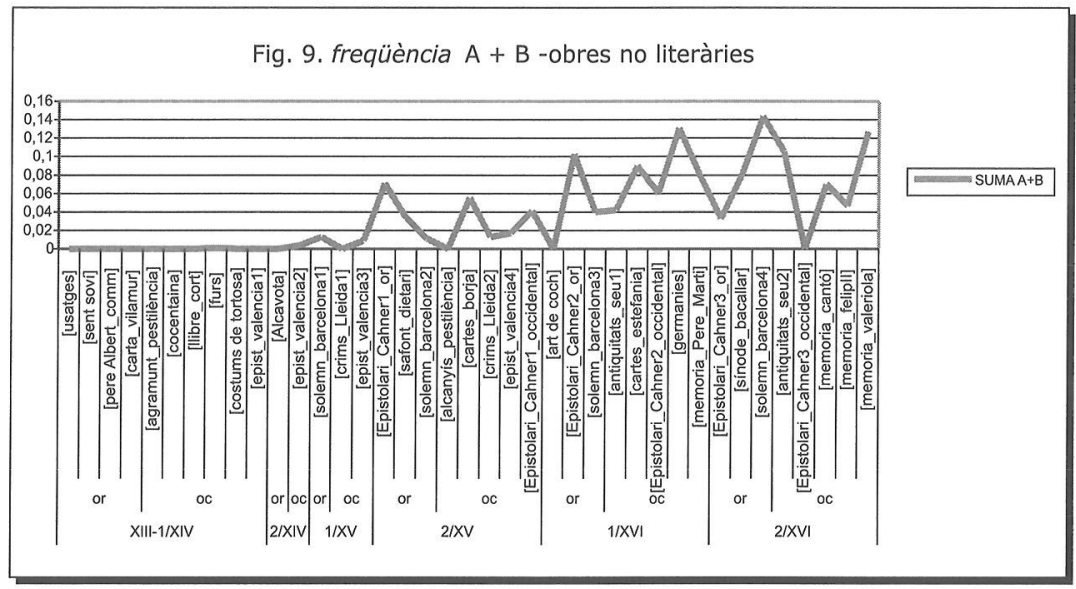

Cal afegir ací un fet important, que enllaça la projecció dels esquemes a noves realitats amb modulacions més profundes en la categoria. En particular, el naixement del sentit B provoca un canvi en el centre prototípic de la categoria (efecte de prototipiciat 1, cf. Geeraerts 1997:22).

$\mathrm{Si}$ atenem a les dades de les figures 4 i 5 comprovarem que ja en la segona meitat del segle XV, però sobretot, durant tot el segle XVI, el sentit B 'venir fins a un punt que es pren com a terme del moviment' esdevé més freqüent que no pas A. Aquesta dada corrobora un fet lògic: el sentit A és menys freqüent atés que es restringeix a contextos exclusivament marítims; per tant, s'il·lustra que la projecció cap a una realitat menys restringida té un efecte quantitatiu important. Com més freqüència d'ús d'un sentit determinat, més possibitats de venir a ser el representant de la categoria en la ment del parlant.

Hi ha un altre fet bàsic que corrobora la substitució de centre prototípic de la categoria. El valor d'arribar B no és sols estadísticament dominant; és, a més a més, estructuralment dominant, perquè d'aquest depenen i naixen nous sentits, la gran majoria, a partir del segle XV.

Hem representat en forma de xarxa (cf. figura 11) l'eixamplament progressiu de la categoria a partir del nou nucli semasiològic, el sentit B. Ens basem en els estudis de Geeraerts (1997) sobre el mot legging del neerlandés, Soares da Silva (1997) per a deixar en portugués i Martines (2000), en relació amb el verb estimar del català. 


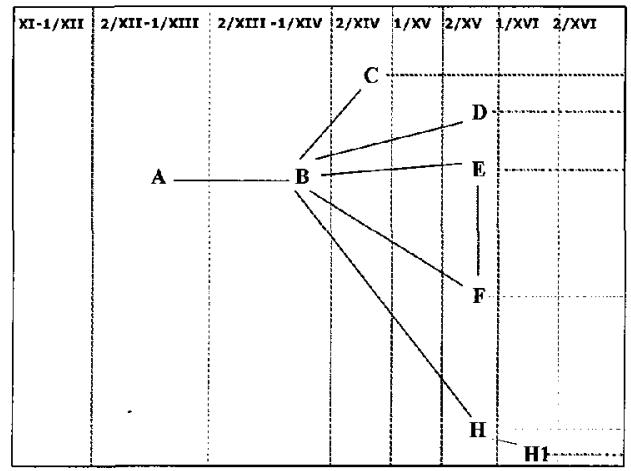
A 'venir fins a la vora, tocar terra"12
E 'venir una cosa o persona després d'un procés a un punt final d'aquest procés'
B 'venir fins a cert lloc (que es pren com $F$ a terme del moviment)'
C 'esdevenir el temps o els fets esperats o H 'estendre's fins a un lloc' preparats d'estona'
D 'venir alguna cosa, transportada per Hl 'estendre's fins a un lloc, ocupar' algú'

Fig. 11. Xarxa de sentits d'arribar i descripció dels sentits.

A primer colp d'ull, la xarxa ja fa llum sobre 1'estructura que pren la categoria a partir del segle XV. D'una banda, hi ha un nucli, cl sentit $B$, que roman intacte, i una perifèria que, de retop, es torna més i més extensa a partir d'aquest sentit $B$ (sentits $C, D, E, F, H$ i $\mathrm{H}$, enllaçats amb B, mitjançant)

En segon terme, s'hi pot constatar que aquest eixamplament no es produeix solament a partir del centre prototípic, sinó a partir de l'enllaç dels altres sentits. Així, per exemple, com veurem a continuació, el sentit que hem anomenat $F 1$ naixa a partir d'F, i, per tant, comparteix trets amb el sentit $\mathrm{B}$, però indirectament. Per tant, la categoria s'eixampla a partir del principi de semblances de família (efecte 2, cf. Geeraerts 1997: 22). I un apunt més: el naixement d'un sentit nou sovint no es pot explicar només a partir d'un únic sentit, sinó com a fruit de la influència de sentits diversos. Hem marcat aquesta relació amb i provarem de mostrar-la tot seguit amb els exemples del corpus.

Finalment, de la mateixa manera que en el pas del sentit $A$ al sentit $B$, els sentits nous són el resultat de projeccions de l'esquema principal establit per a $\mathrm{B}$ sobre noves realitats, que el parlant torna a percebre com a similars o relacionades en algun grau. A mesura que l'esquema s'aplica, s'enriqueix gradualment i es transforma.

12 Definim a partir del $D C V B$ (s.v. arribar) 


\subsection{Les transformacions a partir del nou sentit prototípic}

La primera extensió que constatem en el corpus estudiat es produeix ja en la segona meitat del segle XIV. El sentit que pren el verb arribar en l'exemple 28 extret del procés judicial barceloní a una alcavota, publicat per Jaume Riera i Sans, és el de d'esdevenir el temps o els fets esperats o preparats d'estona' (l'hem anomenat C):

(28) Arribada doncs l'hora de vespres del dia esmentat, comparegué, per una part, davant el dit noble governador o l'honorable regent l'assessoria, el dit procurador fiscal, demanant que es procedis a la declaració (Alcavota 2/XIV, p. 235, lín. 14)

El sentit C respon a una transformació metafòrica bàsica, +EL TEMPS ÉS UN OBJECTE QUE ES MOU+, mitjançant la qual conceptualitzem una realitat abstracta, el temps, a partir d'un domini origen, més concret, els objectes en moviment. Ara el temps és el TRAJECTOR i la FITA, el moment en el qual es troba la persona que conceptualitza l'escena. És per aquest darrer motiu que el $\mathrm{CC}$ de lloc normalment no apareix explicitat. El moviment físic desapareix metaforitzat en el transcurs del temps.

Tots els exemples de $\mathrm{C}$ del corpus estudiat estan conjugats en temps que vehiculen l'aspecte perfet, cosa que torna a demostrar les projeccions fins ara estudiades remeten a la focalització de la FITA, en aquest cas el moment últim més important, el moment esperat.

La metàfora +EL TEMPS ÉS UN OBJECTE QUE ES MOU+ és molt bàsica (cf. Lakoff \& Johnson 1980: 63) i va associada a la majoria dels verbs de moviment (passar, anar-se'n, acostar-se, entre d'altres). Per aquest motiu pensem que el naixement d'aquest sentit va ser immediat al naixement del sentit $\mathrm{B}$. No debades, el sentit $\mathrm{C}$ és l'única extensió documentada en el corpus que analitzem en el segle XIV.

A partir d'aquesta data, l'eixamplament de la categoria augmenta notòriament: només en la segona meitat del segle XV naixen els sentits D, E, F i H. En les figures 12 i 13 es verifica que fins a la primera meitat del segle $X V$ tan sols trobem tres sentits, $A, B$ i $C$, en les obres literàries i $\mathrm{A} \mathrm{i} \mathrm{B}$, en obres no literàries, sovint distribuïts de manera diversa, segons els textos. Així, per exemple, com acabem de veure, l'única volta que apareix arribar en El cavaller i l'alcavota pren precisament el sentit C, que no torna a aparéixer en cap altra obra del nostre corpus d'aquest segle.

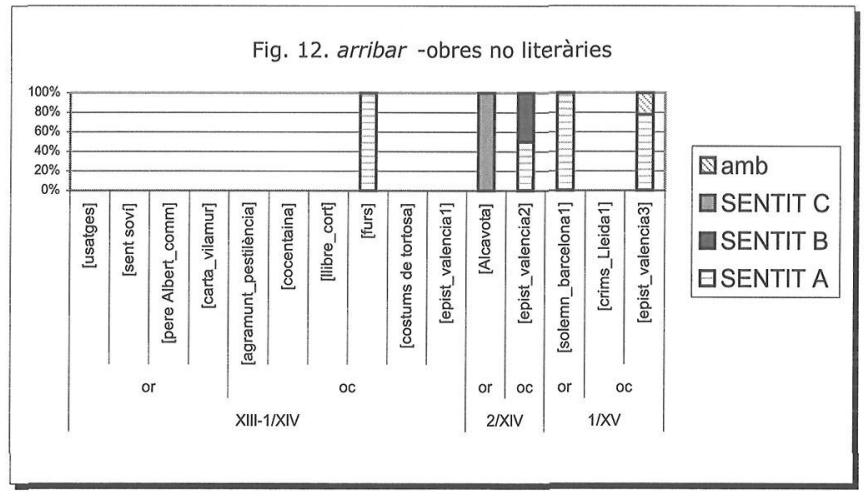




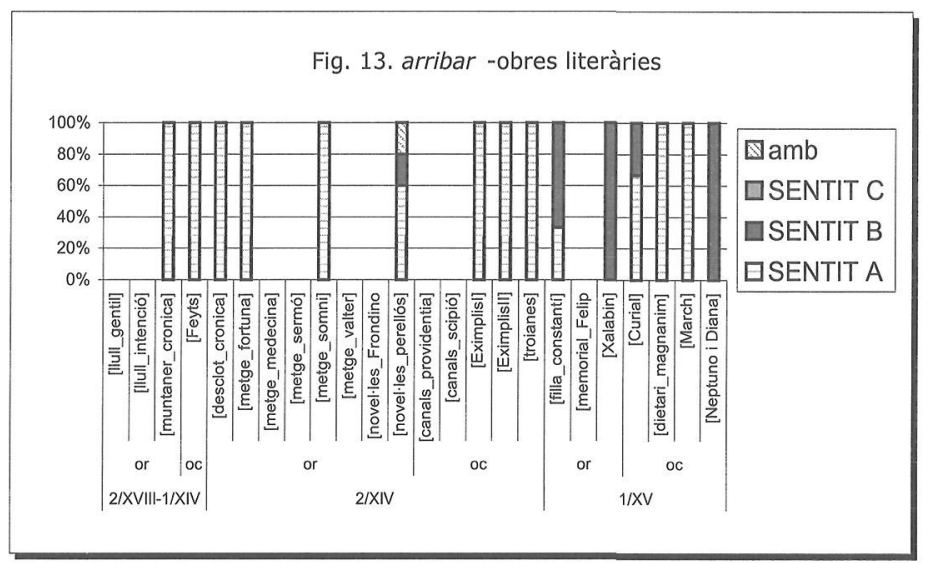

En canvi, en passar a la segona meitat del segle XV (cf. figures 14 i 15) la categoria s'enriqueix progressivament amb sentits nous, tant en textos literaris com no literaris. Fins al punt que en algunes obres literàries com l'Ànima d'Oliver o la Vita Christi, les poques voltes que hi ix arribar presenta ja sentits traslladats.

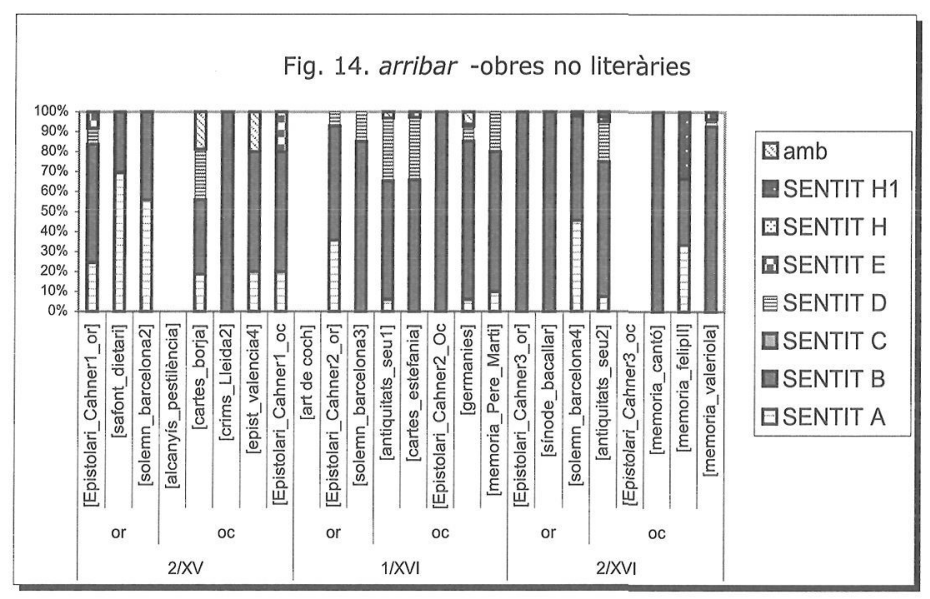




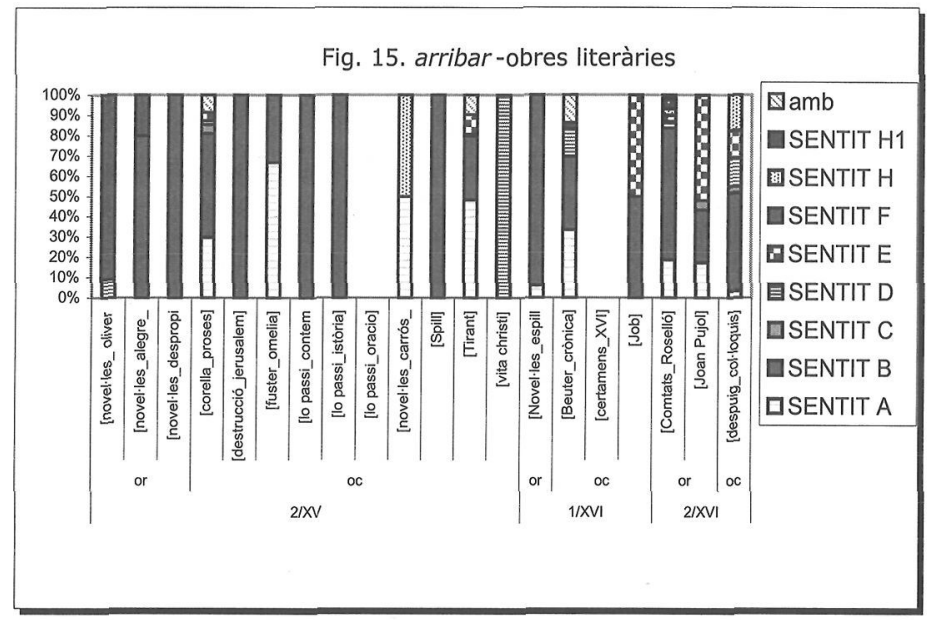

Cal insistir ací que, si el nombre de sentits augmenta, lògicament augmenta també la freqüència d'aparició global del verb arribar. Així ho podem veure reflectit en la figura 16 , per exemple, en les obres no literàries. La gràfica presenta l'augment en la freqüència d'aparició durant el segle XV.

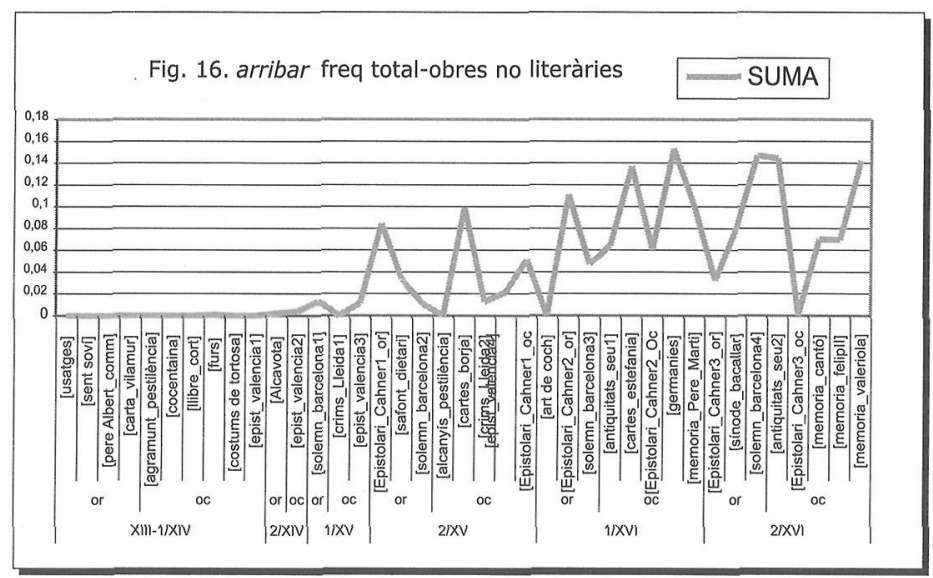

El sentit D 'venir una cosa transportada per algú' apareix en el corpus que treballem a partir de la segona meitat del segle XV en obres literàries occidentals, com la Vita Christi, Corella o el Tirant i també en obres orientals com L'ànima d'Oliver. També en aquesta mateixa època en obres no literàries, com les cartes dels Borges o la correspondència de l'epistolari de Cahner. 
Aquest sentit naix a partir de l'aplicació de la metonímia $+_{L}$ 'OBJECTE TRANSPORIAT PER QUI EL TRANSPORTAt, Així, trobem un objecte no [agent] que pren el paper de TRAJECTOR i es trasllada a una FITA, que és la persona que rep l'objecte transportat. A diferència del sentit metafòric $\mathrm{C}$, ací el moviment encara existeix, però la persona que el fa s'elimina. L'objecte sense moviment propi és, en la majoria de casos, correus (o objectes enviats per correu) i, cncara amb un grau més de metonimització, notícies. Per això, apareix freqüentment en els reculls de correspondència. Per exemple, ja en el XVI apareix fins a 67 voltes en les cartes que s'envien Estefania de Requesens i sa mare Hipòlita Roís de Liori. I, també per això mateix, és freqüent l'arribada de notícies en obres que reconten fets diversos, noves interessants ocorregudes en l'època, com ara el Llibre d'Antiquitats de la Seu de València (10 casos en la primera meitat del segle XVI i 8 casos en la segona meitat).

(29) E venint en lo camí, arribat en Vilafrunca, m'arribà un correu ab breu de vostra santedat, lo qual to nincio me remès (Cartes_borja 2/XV, p. 51, lin. 10)

(30) Sus ara és arribada nova que lo cardenal d'Espanya és millorat molt, però no es té esperança haja a campar d'aquesta malaltia (Cartes_borja 2/XV. p. 98, lin. 15)

La figura 17 ens presenta les estructures possibles d'aquesta nova projecció.

ESQUEMA BASIC $\rightarrow$ SENTIT D

\section{DIRECCIÓ+FITA \& 129}

\begin{tabular}{|c|c|}
\hline $\begin{array}{l}\text { DIRECCIÓ+ FITA } \\
\text { subjecle+CCL \& } 49 \\
\text { subjecte+CCL (9) \& } 69\end{array}$ & $(91,4 \%)$ \\
\hline $\begin{array}{l}\text { DIRECCIÓ+FITA + yques } \\
\text { subjecte+CCL }(\varnothing)+\text { CCL \& } 11\end{array}$ & $(8,52 \%)$ \\
\hline
\end{tabular}

Fig. 17. Imatge esquemàtica bàsica d'arribar, sentit D

En $D$ es repeteix l'estructura d'esdeveniment tèlic que hem estudiat en parlar dels sentits $\mathrm{A}$ i B, no debades $\mathrm{D}$ és una projecció del mateix esquema. A diferència, pcrò, dels esquemes anteriors $\mathrm{A}$ i B, l'esquema $\mathrm{D}$ no apareix combinat mai amb la MANERA, la CAUSA, la COMPANYIA, etc. Per contra, l'ORIGen sí que hi té certa rellevància. Ix un $8,52 \%$ de les voltes: un esquema més recurrent, doncs, que no pas en A $(2,1 \%)$ o B $(2,8 \%)$. L'explicació és senzilla: el receptor de l'ajuda, les cartes o els obsequis, normalment desitja saber qui és la persona que els tramet.

De la mateixa manera, són més freqüents les formes verbals en aspecte perfet $(28,6 \%)$ o perfectiu $(60,4 \%)$ i molt escasses les formes en imperfectiu. Tot i això, el tant per cent de formes en aspecte imperfectiu ha apujat lleugerament (10,8\%) (cf. figura 18). Aquest augment pot ser degut a l'habitualitat que es deriva de rebre correu freqüentment, per exemple: 
(3I) En aquests dies passats, veent l'il.lustrissimo senyor duc que tant temps passava que: no havia rebut lletres de vostra santedat, ni correus arribaven $i$ tampoc se partien d'aci per qui pogués escriure, deliberà trametre a mossèn Hierònim Llòpiz a vostra santedat ab lletres (Cartes borja 2/XV, p. 159, lin. 5)

ASPECTE ARRBAR -SENTITD

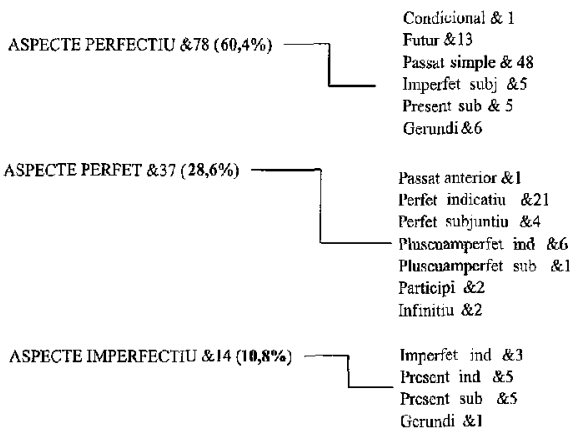

Fig. 18. L'aspecte cn els temps verbals d'arribar D.

També, com en la resta de sentits d'arribar analitzats fins ara, són normals les marques temporals (cf. 30).

Força menys freqüent que el sentit $\mathrm{D}$ en el corpus que hem analitzat ( 21 voltes en tot el corpus) és el sentit E, que apareix també durant la segona meitat del segle XV. En aquest cas, arribar s'espccialitza en l'expressió dels estats. Aixi, a partir d'aqueix moment, gràcies a una nova transformació metafòrica, +ARRIBAR A UN ESTAT ÉS ARRIBAR A UN LLOC+, el TRAJECTOR esdevindrà una persona o cosa que experimenta un procés que la du a un estat nou, la FITA. El moviment despareix, doncs, a favor del canvi. Ací també la projecció metafòrica ćs fruit de la reconversió que fa el parlant de les relacions dels diversos elements que desbrina observant l'escena en moviment. El conceptualitzador descobreix la contiguitat entre el moviment $i$ el procés i focalitza aquest darrer element. El converteix, aleshores, en scntit principal de la categoria.

(32) Tu, Plaerdemavida, pensaves no et restava major benaventurança que morir, i creies que la vida per pus no t'acompanyava, sinó que en major grau sentisses lo multiplicar dels mals que recites, dels quals encara no et deus recordar; fins que arribada als esdevenidors desigs, per fer majors los teu delits, te'n recordes (Tirant $1 / X V$, pàg. 998, cap. CCCLXXX, Iin. 12)

(33) Encrueliren-se los hòmens y començaren llurs crueltats ab los pobres animals [...] y arribà a tant aquesta cmeltat que après que ls bous, de vellesa, no podían llaurar, se'ls menjaren (Comtats_Rosselló 2/XVI, p. 226, lin. 8)

Cap dels 21 casos està conjugat en un temps imperfectiu, cosa que coincideix amb el fet que en els canvis d'estat s'acostuma a visualitzar no la situacio pròpiament en desenvolupament, sinó més aviat el resultat de l'acció; en altres paraules, la part última del canvi. 
Relacionat directament amb el sentit E, trobem, tambć en la segona meitat del segle $\mathrm{XV}$, el sentit $\mathrm{F}$ 'csdevenir un a siluació o procés en algú' que podríem qualificar com a metafòric del tipus teLS ESTATS SÓN OBJECTES QUE ES MOUEN+. En aquest cas, l'csquema és l'invers respectc de $\mathrm{E}$ i ara el TRAJECIOR és l'estat i la FITA, la persona que l'experimenta. Així l'[experimentador] espera que li arribe la mort, en l'exemple 34, i Francesc Alegre, en l'exemple 35, es pregunta sobrc l'arribada de l'amor:

(34) Mes que parega a la mia fi, no ho cregues, perquè a la misericòrdia de Déu plagué donar-me temps, i gran, ab què pogui penedir-me, i em perdonà la culpa; la justícia del qual ordenà en aquest lloc sia mon purgatori, fins que arribe lo terme per què fui creada (Novetles_l'ànima d'oliver 2 XY, p. 143, lin. 3)

(35) - Oh laureat poetal si veres són les llaors que de vós la fama escampa, prenent, no testimonis estranys, mes les obres que a vós sobreviuen, socorreu-me declarant què és açò que, mos ulls ocupant, mon cor en dubte té, no sabent descernir per on, ni on arribat sia (Novel.les_alegre_somni 2XXV, p.125, lin. 5)

En tractar el sentit $\mathrm{A}$, hem pogut observar que en alguns casos el predicat d'assoliment pot esdevenir una realització, sobretot si el verb arribar es troba conjugat en present o imperfet, temps verbals que vehiculen l'aspecte imperfectiu. En aquests casos hem constatat que l'acció s'obscrva amb certa duració, tot i que sempre és tèlica. Possiblement, a partir d'aquests contextos el parlant infereix que arribar també pot expressar una acció progressiva. Pensem quc solament a partir d'aquesta inferència es pot explicar el naixement del sentit $H$ 'estendre's una cosa fins a cert lloc', que trobem en la segona meitat del XVI:

(36) Per lo que ara miram en tota aquella comarca y per lo que veiem, lo discurs que cadal dia fa la mar y també lo que en escriptura trobam aont se arreplegaven les armes dels reys per a fer algunes empreses, venim a enténdrer y crèurer que és així, que la mar arribava als llochs que tinch dits (Despuig_col-loquis 2/XVI, p. 146, lin. 31)

(37) /.../ començuren los llurs balls a l'entorn dels focs, que, per ésser ells tan grans, ab la altitut de la dita montanya aparia als habitants de ditas valls que aquell foc arribava al cel (comtats_Roselló 2/XVI, p. 189, lin. 17)

En aquest sentit nou, sí que és projectat el sentit de moviment de l'esquema B. En aquest cas, però, el TRAJECTOR és un líquid que es desplaça cap a un lloc, la Frit, on finalitza el seu moviment. A diferència, però, de 1'esquema prototípic del verb arribar, en el sentit $\mathrm{H}$ allò que es focalitza és el CAMi, és a dir, d'on parteix i fins a on arriba aquest líquid i l'extensió que recorre. Ho corrobora el fet que dels nou casos que hem trobat de $\mathrm{H}$ en el corpus, sis estan conjugats en imperfet d'indicatiu, un en present d'indicatiu $i$ un cn gerundi, tots els tres temps imperfectius. Tambć hi ha un únic cas de futur, que pot interpretat-se també com a imperfecliu:

(38) Don Pedro: Si és, per cert. ¿Això, senjor, quens aveu dit de la mar, que en lo temps antich arribà fins Amposta és cosa certa? (Despuig_col-loquis 2/XVI, p. 146, lín. 25) 
De la mateixa manera, són majoritàriament imperfectius els casos d'arribar dels exemples següents de la primera $\mathrm{i}$ segona meitat del segle XVI:

(39) La segona cosa és que si Edeta era distinta de Lèria i prop de Sagunto, no podia ser sinó esta ciuiat de qui parlam. Deias, doncs, Edeta, de la qual prenia lo nom tot lo trast dels edetans, que arribava fins a Saragossa, que llavons no era tan gran cosa com Edeta regnava (Beuter_crònica 1/XVI, p. 134, lin. 10)

(40) se restaren a la part de la epistola de la dita capella, que es devers la sacristia, ahont tenien ja aparellats quatre banchs llevadissos, molt llarchs, que arribaven desdell primer pilar fins a un altro pilar que y ha detrás lo altar de dita capella (Solemn_barcelona4 2/XVI, p. 116, lin. 19)

A diferència dels exemples de $H$, en aquest nou eixamplament de la categoria, $i$ aixi com també ha ocorregut en els sentits D, E, i F, un dels elements principals de l'esquema prototípic d'arribar, el moviment, desapareix en favor d'un tret més perifèric, on aquest cas, 'l'extensió'.

Els exemples 39 i 40 són una bona mostra de la hipòtesi del fictive-motion ("moviment fictici') proposada per Talmy (1996b), Cifuentes (1999: 112-113) i Palmer (2000: 119), que serveix per a fonamentar la idea de les projeccions dels esquemes en les escenes de moviment. Hem anomenat aquest nou sentit $\mathrm{Hl}$ i apareix huit voltes en tot el corpus.

\section{Conclusions}

Comptat i debatut, en aquest treball hem intentat establir quins han sigut els inicis del verb arribar. En primer lloc, hem observat com el verb arribar estableix el significat prototípic actual a les darreries del segle XIV --tot $\mathrm{i}$ que hi ha exemples de principis del segle XIV-, a partir d'un canvi semàntic que tan sols es pot explicar a partir de l'experiència del poble català amb la mar. Així, el verb arribar passa a significar 'venir (les barques) cap a la riba' a 'venir a un lloc determinat'. S'ha insistit que el valor d'arribar B reemplaça el sentit primigeni A i que, per tant, la categoria no solament creix sinó que, a més, canvia de prototipus (efectc de prototipicitat 1). Aquest nou prototipus esdevindrà amb el temps més freqüent $i$, de més a més, vindrà a ser estructuralment dominant, ja que a partir d'aquest $i$ en un espai de temps relativament curt - mig segle, a tot estirar - la categoria augmentarà amb sentits nous, que, al seu torn, seran l'origen d'altres sentits en segles posteriors.

Hem mostrat, per tant, que a partir del sentit B i durant la segona meitat del segle XV, la catcgoria representada per arribar s'eixampla progressivament. De més a més, hem pogut observar que aquest eixamplament és el resultat, d'una banda, de projeccions metafóriques (cf. arribar B, arribar C, arribar E...), que transformen trets diversos, com el moviment; i de l'altra, és el resultat de projeccions metonímiques (cf. arribar D, arribar H...), que conserven el moviment, però transformen l'esquema quant a altres aspectes, per excmple focalitzant el CAMi en lloc de la FITA, un dels elements principals de l'esquema B. Amb aquest fet es demostra una de les característiques principals de les categories, la gradualitat, atés que per al naixement de sentits nous hi ha elements de l'esquema principal que esdevenen rellevants i d'altres, secundaris. 
En tercer lloc, s'ha pogut constatar que el creixement de la categoria no es fa exclusivament des del sentit $B$, sinó que aquesta pot eixamplar-se a partir de sentits traslladats, cosa que demostra que cal entendre aquesta modulació a partir del principi de semblaça de família (cf. arribar H1), és a dir, en termes d'estructura radial ('raïm de sentits', efecte dc prototipicitat 2 ).

Finalment, hem volgut presentar que les dades quantitatives poden fer llum cn alguns punts de l'estudi de l'evolució semasiològica d'un verb, en aquest cas, arribar. Evidentment, les dades quantitatives no poden suplir les dades qualitatives, ni tan sols esdevenir la base indiscutible d'un estudi d'aquestes caracteristiques. Tanmateix, ens han proporcional avantatges, relacionats amb l'establiment d'index de freqüència. Concretament: ens ha permés justificar l'establiment d'un prototitpus: així, en analitzar l'eixamplament de la categoria del verb arribar, hem observat que l'augment de l'aparició de la freqüència d'un sentit pot ser una prova indicativa — no l'única- de la creació d'un nou sentit prototipic.

\section{ReFirènCIES Bibliogràfiques}

Bastardas, Joan (1995): La llengua catalana mil anys enrere, Barcelona, Curial.

Bastardas, Joan (1996): Diàlegs sobre la meravellosa historia dels nostres mots, Barcelona, Ed. 62.

Cifuentes Honrubia, José Luis (1994): Gramática Cognitiva. Fundamentos Críticos, Madrid, Eudema.

Cifuentes Honrubia, José Luis (1999): Sintaxis y semántica del movimiento. Aspectos de gramática cognitiva, Alicante, Instinuto de cultura Juan Gil-Albert.

DECat = Coromines, Joan (1983-1991): Diccionari Etimològic Complementari de la Llengua catalana, 9 vol., Barcelona, Curial \& La caixa.

Geeraerts, Dirk (1997): Diachronic Prototype Semantics. A contribution to Historical Lexicology, Oxford, Clarendon Press.

Johnson, Mark (1987): The body in the mind: The Bodily Basis of Meaning, Inagination, and Reason, Chicago, University of Chicago Press.

Lakoff, George \& M. Johnson (1980): Metáforas de la vida cotidiana; Cátedra, Madrid, 1995. [3 $3^{\mathrm{a}}$ edició en espanyol. Traducció de Lakoff, George \& M. Johnson, (1980): Metaphors we live by, University of Chicago Press, Xicago.]

Lakoff, George (1987): Women, fire and dangerous things. What categories reveal about the mind, Chicago, The University of Chicago Press.

Lakoff, George (1990): «The invariance hypothesis: is abstract reasoning based on image-schemas?», Cognitive Linguistics, 1.1, págs. 39-74.

Langacker, R. W. (1987): Foundations of Cognitive Grammar I: Theoretical Prerequisites, Standord University Press.

Langacker, R. W. (1990): Foundations of Cognitive Grammar, vol. 2, Standford, California, Standord University Press.

Martines, Josep (1998): «Creativitat lexica. Passat i present). En Un món de llengüies. Actes de les $V$. VI. VII i LX Jornades de Sociolinguiistica de la Nucia, Maria Antònia Cano \& Josep Martines \& Viccnt Martines (eds.), Alcoi, Ed. Marfil, pp. 171-195.

Martincs, Joscp (2000): «L'expressió de les emocions i la creativitat lèxica: 'estimar'/ 'amar'. Fntre l'cufcmisme i la metáfora cultural), En Actas del VIII Congreso Internacional de la Asociación Hispánica de literatura Medieval, Santander, Universidad Menéndez Pelayo, vol. 2, pp. 12211243.

Palmer, Gary B. (2000): Linguilstica cultural, Alianza Editorial, 2000. 
Pérez Saldanya, Manuel (2002): «Les relacions temporals i aspectuals». En Solà, Joan, Maria-Rosa Lloret, Joan Marscaró y Manuel Pérez Saldanya (dirs.), Gramàtica del Català Contemporani, Barcelona, Empúries, págs. 2567-2728.

Ramos Alfajarín, Joan Rafacl (2000): Els verbs ésser, estar $i$ haver(-hi) en català antic, Valencia/ Barcelona, Institut Interuniversitari de Filologia Valenciana, Publicacions de l'Abadia de Montserrat.

Soares da silva, Augusto (1999): A semântica de deixar. Una contribuçâo para Abordagem Cognitiva em Semântica Lexical, Braga, Fundaçâo Calouste Gulbenkian, Fundaçâo para a Ciencia e a Tecnologia.

Talmy, Leornard (1996a): «The windowing of Attention in language». En M. Shibatani \& S. Thompson (eds.): Grammatical Constructions: Their Form and Meaning, Oxford, Oxford University Press, págs. 235-287.

Talmy, Leornard (1996b): «Fictive Motion in Language and 'Ception"». En P. Bloom, M. A. Peterson, L. Nadal i M. F. Garrct (eds.) (1996): Language and space, Cambridge, MIT Press, págs. 211-276.

Vendler, Zeno (1967): Linguistics in Philosophy, Ithaca, Cornell University Press. 